\title{
Ética na administração pública: desafios e possibilidades'
}

\author{
Nanci Fonseca Gomes \\ Pesquisadora independente
}

\begin{abstract}
Este artigo discute aspectos da conduta moral presentes no trabalho na administração pública. As discussões baseiam-se em reflexões de pensadores da teoria crítica, em particular em Adorno, Horkheimer e Marcuse, na psicanálise de Freud e em tese de doutorado em psicologia. As análises são apresentadas a partir da percepção de aspectos da moralidade em ocupantes de cargos de chefias em órgãos públicos, entrevistados para a pesquisa de doutorado. Apresentam-se os efeitos e manifestações de dois aspectos na conduta ética no contexto do trabalho no serviço público: a racionalidade da administração pública; e a moralidade do indivíduo. A relevância do estudo está em apontar alguns atributos importantes a serem fortalecidos nos indivíduos, bem como a relevância da autorreflexão como fatores fundamentais na conduta ética.
\end{abstract}

Palavras-chave: ética; gestão pública; conduta moral.

Ética en la administración pública: desafíos y oportunidades

Este artículo discute los aspectos de la conducta moral que están presentes en el trabajo en la administración pública. Las discusiones se basan en reflexiones de pensadores de la teoría crítica, particularmente en Adorno, Horkheimer y Marcuse, en Freud y en la tesis de doctorado en psicología. Los análisis que se presentan se basan en la percepción de los aspectos de la moralidad en la ocupación de puestos de liderazgo en los organismos públicos, entrevistados para la investigación doctoral. Presenta los efectos y manifestaciones de dos aspectos de la conducta ética en el contexto del trabajo en la administración pública: la racionalidad de la administración pública y la moral de la persona. La relevancia de este estudio es señalar algunos atributos importantes que deben reforzarse en los individuos, así como la relevancia de la autorreflexión como factores clave en la conducta ética.

Palabras clave: ética; administración pública; conducta moral.

DOI: http://dx.doi.org/10.1590/0034-76121714

Artigo recebido em 6 set. 2013 e aceito em 25 abr. 2014.

${ }^{1} \mathrm{O}$ artigo tem como base a pesquisa de doutorado intitulada: Conduta moral na administração pública: uma experiência com gestores públicos, de minha autoria, apresentada em 2010 na Universidade de São Paulo, no Instituto de Psicologia. 
Ethics in public administration: challenges and opportunities

This article discusses the moral conduct aspects present in public administration workplace. The discussions are based on reflections on the critical theory thinkers, especially on Adorno, Horkheimer and Marcuse works, on Freud's psychoanalysis and on Psychology PhD Thesis. The analysis is presented from the perception of morality aspects on holders of management positions, who were interviewed to the PhD Thesis research. Effects and manifestations of two aspects on the ethical behavior are presented in the context of public services workplaces: the rationality in public administration; and the morality of the individual. The relevance of this study is on pointing out some important attributes to be strengthened in the individuals, as well as the relevance of self-reflection as key factors in ethical conduct.

KEYWORDs: ethics; public management; moral conduct.

\section{Introdução}

A corrupção é a expressão dos valores de uma dada cultura que justifica a exploração de uma pessoa sobre outra e que condecora o mais "esperto e perspicaz". Ela expõe a falência da ética que garante a vida e que é baseada na consciência de que cada ação pessoal se reflete no contexto social e no universo particular do indivíduo.

Quando praticada na administração pública, a corrupção expõe um universo de inversão de valores no qual prevalecem interesses particulares em detrimento dos interesses públicos.

Este artigo busca discutir sobre a consciência nos indivíduos que trabalham na administração pública e de verificar como ela se expressa no comportamento ético nesse contexto. Buscou-se discutir quais preceitos morais orientam a conduta no trabalho no serviço público. A pesquisa de doutorado que subsidia este artigo teve um enfoque social e psicanalítico freudiano e partiu de duas hipóteses. Uma, de que há fatores no próprio modo de funcionar da administração pública que favorecem a não observância da moral e dos preceitos éticos. Outra, que a própria formação pessoal do indivíduo, tanto pelo contexto social quanto pessoal, pode favorecer ou dificultar a conduta ética no trabalho.

O estudo teve como fundamentação a teoria crítica, especialmente os autores Theodor Adorno, Max Horkheimer, Walter Benjamim, Herbert Marcuse, e, também, se fundamentou nas reflexões de amplitudes social e cultural realizadas por Sigmund Freud. Foram confirmados pelo estudo realizado na pesquisa que tanto o modo de funcionar da administração quanto a formação do indivíduo implicam, de forma contundente, a ética presente no trabalho no serviço público.

Compreendendo aspectos originários da moralidade presente na atualidade, o objetivo do presente artigo é apontar aspectos a serem fortalecidos no indivíduo, destacar a reflexão e um modo especial de se relacionar com o trabalho que o indivíduo realiza, de forma a interceder na postura ética no trabalho.

Os participantes entrevistados na pesquisa de doutorado foram ocupantes de cargos comissionados - denominados de gestores por gerenciarem áreas, equipes e/ou projetos, e suas 
conclusões podem ser estendidas aos ocupantes de diferentes cargos e funções com diversos vínculos nas repartições e instâncias públicas.

\section{A formação da moralidade e da ética na sociedade: contribuições da teoria crítica e de Sigmund Freud}

A ética pode ser considerada ação humana balizada em valores e princípios ligados ao bem comum. Para construir uma ação ética, o indivíduo precisa ter certas habilidades que o tornem capaz de discernir para fazer escolhas, compreendendo que elas repercutem em si mesmo, no outro e no coletivo: ser autônomo, consciente de seus atos, atitudes e atividades, tendo clareza de suas finalidades e relacionando-as com a sua vida e a dos outros seres. A conduta ética pressupõe consciência e autonomia (Maia, 1998:152).

A vida reduzida ao mero consumo e configurada de forma utilitarista afasta a possibilidade da ética e da consciência; é inviável buscar compreender a ética e a moralidade sem considerar a vida humana na contemporaneidade, e é imprescindível refletir sobre o indivíduo no funcionamento social e nas relações humanas que ele integra (Adorno, 1993:7). A noção de ética está relacionada à condição de constituição da sociedade e da cultura vigentes. A ética pressupõe a superação do estado natural para um estado cultural, civilizatório, de emancipação da consciência, e a consideração dos outros seres para uma convivência coletiva, suposição prejudicada nesta sociedade (Marcuse, 1982:21).

Há uma contradição existente nessa sociedade: enquanto o progresso e suas realizações, "produtos da capacidade intelectual da humanidade", poderiam ser capazes de criar "um mundo verdadeiramente livre", o indivíduo, ao contrário, torna-se cada vez mais "eficaz na subjugação e destruição do homem pelo homem" (Marcuse, 1982:22).

A liberdade é um requisito fundamental da ética. Nela está implícito o exercer da razão, contrapondo-se às paixões e à submissão cega às pulsões. Nas condições objetivas da sociedade em vigor, a liberdade e a razão não têm sido exercidas pelos indivíduos, acentuando ainda mais a alienação (Marcuse, 1982:8).

Sendo a liberdade fundamental no exercício da ética, ela só pode ser exercida, de fato, numa sociedade justa. O indivíduo numa sociedade diversificada e rica em possibilidades, podendo fazer escolhas, desenvolve suas potencialidades numa ambiência na qual a tensão vivida, por causa das exigências desse universo da necessidade — as paixões e as obrigações da sociedade — , estaria amenizada (Marcuse, 1982).

A ética permite a vida em coletividade com o controle das pulsões (Freud, 1988). Freud define três sofrimentos humanos: a) o poder superior da natureza, b) a fragilidade do próprio corpo e c) o relacionamento entre as pessoas. Freud aponta que a fonte de maior sofrimento é, justamente, o relacionamento com os outros sujeitos. O homem tem a necessidade de uma "ética", ou seja, da criação de regras que visam ajustar os relacionamentos mútuos em sociedade.

Segundo Freud (1988), a pulsão exige do sujeito a sua satisfação e a civilização impede a realização dessas exigências pulsionais: o mal-estar se instala no indivíduo, é gerado um 
conflito interno e em relação à cultura, que impõe regras e impossibilita a realização dos desejos. Freud aborda o antagonismo entre o indivíduo e as exigências sociais que determinam a forma psíquica da moral. Devido à determinação repressiva, as pulsões são canalizadas pelo recalque e formam o superego; e, pela sublimação, correspondem aos ideais estabelecidos pela cultura, e, desses, se estabelece a moral individual.

Há uma mobilização constante das energias psíquicas no indivíduo, em sua relação consigo mesmo e com a sociedade, exigências que colocam permanentemente em questão a moralidade. O processo civilizatório exige do sujeito a saída do estado bárbaro para aquele que sucumbe suas pulsões, sendo fundamental saber submeter-se a leis e regras comuns, que vão dar os contornos morais da convivência coletiva (Freud, 1988).

$\mathrm{Na}$ atualidade o grande desenvolvimento tecnológico e o saber humano não têm levado a um desenvolvimento da humanização. Em "Elementos do antissemitismo", Horkheimer e Adorno (1985:160) discorrem sobre uma falsa ordem social que produz uma "coletividade bárbara", que leva à regressão, à violência, na qual os indivíduos estão integrados. Indivíduos "obcecados e privados de sua subjetividade". Os autores apontam que, na realidade, essa ordem só é possível de ser mantida se ela desfigurar os homens e, consequentemente, sem poder para se separar dessa ordem, os homens agem como bárbaros.

Cada indivíduo busca satisfazer "seu próprio inferior bem-estar", apegando-se "à vida habitual", e acaba por submeter-se cegamente a "forças determinantes" que estão desamarradas e "alheias à vida". O sujeito acaba por limitar-se em sua capacidade intelectiva, chegando à estupidez: "o dinheiro está, de modo devastador, no centro de todos os interesses vitais, e é exatamente este o limite diante do qual quase toda relação humana fracassa" (Benjamim, 2000:21-22).

A questão econômica é importante para discutir a ética na atualidade, mas não é única. Um dos problemas fundamentais da ética vivida é o fato de a racionalidade e a técnica terem sido colocadas no lugar do humano (Horkheimer e Adorno, 1985).

Conforme afirma Benjamim (2000) cabe aos indivíduos que não estão totalmente absorvidos por essa lógica um trabalho de grande esforço para infundir na realidade o próprio "calor" no sentido de evitar a frieza absoluta. A brutalidade tem sido uma das respostas de adaptação possíveis dos indivíduos diante da lógica da sociedade que "negocia a vida" (Horkheimer e Adorno, 1985:162).

A possibilidade de o indivíduo ser autônomo e consciente nessa sociedade administrada está prejudicada, porque a alienação tem sido o resultado de sua formação e, na impossibilidade da consciência, fazem-se distantes a vida ética e a prática ética. Faz-se necessário ir além da simples constatação de que não há uma vida ética, mas interrogar o que leva essa sociedade à barbárie e a não considerar a ética na vida em sua plenitude.

Nas passagens em que este estudo se refere à ética, está implícito no termo o seu sentido como intenção e busca, e não como possibilidade exercida de forma plena, conforme descrito anteriormente.

Discussões sobre a ética no serviço público têm ocorrido com mais intensidade no Brasil desde as manifestações sociais ocorridas em junho de 2013. A importância da discussão do 
tema neste artigo se dá pelo fato de que este apresenta propostas educacionais, com contribuições da psicanálise da teoria crítica, para auxiliar na alteração de parte dessa realidade. Essas ações educacionais visam favorecer com que os indivíduos resistam à violência nos pequenos atos, sendo éticos ao considerar o outro, podendo também viabilizar a concretização do interesse público na justa prestação de serviços à sociedade.

\section{0 que procurar nas pessoas para buscar a ética?}

Nos escritos acessados, e em especial em Adorno (1993) e Horkheimer e Adorno (1985), podem-se levantar inúmeras citações diretas e indiretas sobre atributos da moralidade dos indivíduos importantes para o exercício da ética.

Destacam-se aqui alguns desses atributos a serem preservados. São eles: solidariedade, senso crítico e estranhamento, capacidade de julgamento, justiça, compaixão, comprometimento, identificação ou comoção com o sofrimento alheio, força dos interesses privados diante de escolhas, consciência, alienação e resistência à violência e à violação.

Adorno aponta a importância da sensibilidade, viável apenas num mundo que não se baseasse na coerção, na apropriação e na falsa multiplicidade (Adorno, 1993:199). Pode-se afirmar que a sensibilidade é um valor fundamental para a solidariedade, no sentido de propiciar a percepção do outro e do sujeito para mais além que objetos a serem apropriados.

A percepção do homem está deformada, e isso não ocorre por influências que vêm de fora dele, nem é expressa apenas nos papéis que desempenha, mas é constituinte de uma sociedade doente que gera pessoas sem vida que lutam pela autopreservação (Adorno, 1993:201).

Quem não responde da maneira como a totalidade espera e que encara a todos como mercadoria, sente-se estranho e não natural. A irracionalidade do sistema social imprime no indivíduo a perseguição em satisfazer interesses escusos e particulares, tornando-se conduta comum e esperada aos indivíduos; o estranhamento passa a ocorrer se o indivíduo não reage como esperado. Diante de um terror generalizado, "a estranheza é o antídoto para a alienação" (Adorno, 1993:81).

As pessoas se conformam com a "barbaridade", agem como se ela não lhes dissesse respeito, não a estranham e não a experimentam mais. Conforme aponta Adorno (Adorno, 1993:10), "o indivíduo ganhou tanto em riqueza, diferenciação e força quanto, por outro lado, se viu enfraquecido e tornado oco pela socialização da sociedade". O estranhamento, o senso crítico e a desolação são aspectos componentes da moralidade a serem procurados no indivíduo.

O incômodo e a moral diante das aberrações e dos atos bárbaros que atingem a muitos estão quase ausentes, prevalece no indivíduo uma "obcecada moral micrológica" que surge diante de situações insignificantes, do universo privado. Essa moral ganha um tamanho imenso que o corrói, desloca o "princípio social para a consciência privada". Há, assim, uma falsa solidariedade, uma capacidade ofuscada de julgamento, e quase nenhuma identificação ou comoção com a dor do outro (Adorno, 1993:81). 
O esperado do indivíduo, que estaria moralmente comprometido com a intenção de uma vida justa, é que ele considere os interesses coletivos; entretanto, não significa que a saída seria colocar em prejuízo os interesses singulares. O modelo ético pretendido não pode se efetivar se não se considerar e fortalecer o particular, sem, entretanto, negar o universal. No entanto, o que ocorre na sociedade pautada em relações econômicas é uma falsa valorização do indivíduo.

Conforme nos aponta Adorno (1993), os interesses reconhecidos como particulares na sociedade são produzidos por ela, que, por não encontrar resistência, reforça regredidos interesses narcísicos. Numa cultura narcísica há uma fantasia de plenitude do indivíduo e da desnecessária solidariedade social ou lei social que regule suas relações. Nessa sociedade há o reforço das tendências narcísicas que repercutem na ética vivida. Adorno (1993) conclui que os interesses são produzidos e essa produção se sustenta na falta de consciência, na banalização da vida, na negação tanto do coletivo como do particular.

Tiburi (2001), ao discutir Adorno (1993), descreve que, quando o indivíduo é tomado pelo sentimento de "vergonha, ao participar da injustiça universal", abre caminho para a solidariedade.

Compaixão e solidariedade são outros aspectos componentes da moralidade. Segundo Horkheimer e Adorno (1985), a compaixão é "limitadora e insuficiente" e expressa em sentimentos a confirmação da interiorização no sujeito das diferenças sociais, especificamente entre ricos e pobres. Entretanto, Horkheimer e Adorno (1985:99) afirmam que há de se considerar que há infelicidade nos homens e esta pode ser objeto de lamentações.

Os autores citados apontam que há na compaixão uma contradição inerente. Quando presente nas relações entre os indivíduos, ela ameniza a revolta e a crítica ao todo, atenuando a tirania. Ela colabora com o estado de menoridade dos homens mantendo a ideia de classificação ou categorização dos indivíduos. Por outro lado, a frieza - e nela há a ausência da compaixão - fortalece a indiferença em relação à dor ocasionada pela injustiça e pela opressão. A falta de compaixão retira a possibilidade de identificação com o que o outro está passando (Horkheimer e Adorno, 1985).

\section{0 indivíduo e o trabalho na atualidade}

O aparecimento do conceito de indivíduo coincidiu com o surgimento dos estados nacionais e o término do período medieval. Houve uma transição da essência em comunidade para essência singular. O indivíduo que "nasce" no século XVIII assume funções na cadeia produtiva e passa a ser reconhecido pelo papel social (chefe, subordinado, operário, gerente, professor, diretor, funcionário público), reconhecimento esse que é engendrado pelas relações sociais e inserido de significado, carregado de ideologia (Adorno, 1995b).

O indivíduo em posse de sua força de trabalho torna-se substituível; o indivíduo como mercadoria tem uma falsa autoconsciência de si, que se "constitui segundo as exigências tecnológicas do processo de produção” (Maia, 1998:166). 
O trabalho, que poderia ser um canal de sublimação de energias pulsionais, não tem servido a esse intuito. As energias voltam-se em parte para o próprio sujeito contra a própria cultura. Por um lado, por não haver canalização via trabalho e, por outro, pela árdua exigência feita pela sociedade aos sujeitos. O indivíduo não se desenvolve plenamente. E, como afirma Marcuse (1979:25), "o mundo do trabalho se torna a base potencial de uma nova liberdade para o homem no quanto seja concebido como uma máquina e, por conseguinte, mecanizado".

Marcuse (1979) descreve que o sistema produtivo foi sempre utilizado com finalidade lucrativa, submetendo os sujeitos que permanecem trabalhando em alienação. O que fazem não tem sentido, não satisfazem as suas necessidades e a libido é desviada para o desempenho socialmente útil para o sistema se manter, não correspondendo aos desejos individuais, cujas exigências impostas são introjetadas como autoridades, operando no sujeito como criações dele: desejos, moralidade e satisfação.

Nos atos e condutas dos indivíduos estão os reflexos dessa formação e da racionalidade social. Segundo Marcuse (1982), no universo do trabalho e da produção está presente a mesma racionalidade da sociedade administrada e o sujeito está formado para compor e ser composto por ela. "A enxurrada de informações precisas e diversões assépticas desperta e idiotiza as pessoas ao mesmo tempo" (Horkheimer e Adorno, 1985:15). Prosseguem os autores: o "saber está a serviço de todos os fins da economia" e a técnica é sua essência. Os autores concluem: "Poder e conhecimento são sinônimos".

Marcuse (1982) esclarece que a racionalidade do sistema afeta a consciência, levando a um conformismo que chama de consciência feliz, que releva as barbáries que ocorrem, vendoas como à margem do mundo civilizado. O poder sobre o homem, adquirido por essa sociedade, é diariamente absolvido por sua eficácia e produtividade (Marcuse, 1982:92).

O trabalho e a forma como estão organizados são reflexos do que Adorno chama de cadeias do pragmatismo, onde a experiência é bloqueada e leva a uma consciência debilitada (Adorno, 1995a: 203 e 212). A técnica e os meios estão independentes, se especializam para atingir os fins e se alienam deste; esse funcionamento aniquilou completamente a discussão (Horkheimer; Adorno, 1985:216).

Baseada nos autores citados, algumas indagações e hipóteses geraram o estudo da pesquisa de doutorado mencionada anteriormente. Uma das hipóteses foi a de que um profissional, ou mesmo um "técnico", como se diz no contexto do trabalho, acabaria por ter a ilusão de sua isenção às finalidades de suas atividades, e, estando alienado dos fins de sua ação, ele atuaria como um ser anônimo, vendo-se apenas cumprindo ordens ou exercendo seu papel técnico, apolítico.

Nas administrações a racionalidade do trabalho e dos mecanismos produtivos, com a multiplicidade de tarefas e de funções, com a departamentalização das áreas e suas respectivas tarefas e preocupações, divide em partes o que cabe a cada um, com as ordens e os ordenamentos ditados por instituições despersonificadas, instâncias anônimas a serem seguidas; criam certa burocracia que assume forma de entidade que rege e destitui cada um e a todos da responsabilidade por qualquer ato (Costa, 1991:65-67). Não é tão raro encontrar, em 
repartições públicas, técnicos que exercem suas atividades burocráticas com finalidades unicamente voltadas para si mesmas, que reagem aos seus automatismos parecendo não haver a percepção do impacto nos indivíduos que precisam ou dependem daquele carimbo ou parecer em processo.

As pessoas se submetem à realidade alienante em maior ou em menor intensidade, dependendo do quanto estão abertas para reflexão e conscientes do processo em que estão inseridas. Pode-se supor, a partir da discussão dos autores e dos resultados da pesquisa de doutorado citada, que a possibilidade de superação dessa submissão ao trabalho está também relacionada à capacidade de o indivíduo se identificar com a finalidade do trabalho que realiza, consciente das condições que o estrutura, sendo capaz de refletir sobre si mesmo nesse contexto.

A maneira de funcionar das organizações e de estruturar as relações de trabalho está sedimentada nos alicerces da sociedade administrada. A racionalidade presente na organização do trabalho imprime, na formação do indivíduo, certa ética que passa pela frieza, a perda da autonomia e da consciência. O pensamento de Adorno (2006:23-43) aponta que há impacto estruturante na formação da consciência, e na autonomia do indivíduo os processos de trabalho vigentes que têm a técnica como força produtiva e a dominação como finalidade.

\section{A racionalidade da máquina pública, a moralidade das pessoas e a implicação na ética}

A racionalidade da administração pública passou por várias fases, constituindo-se sob o impacto de aspectos econômicos, sociais e históricos até chegar aos modelos atuais (Abrucio, 1997).

A racionalidade na administração pública, explicitada no modo de governar e administrar o Estado, foi se consolidando na sociedade ao longo dos anos, passando pelo patrimonialismo no Estado oligárquico; pelo modelo burocrático e, por fim, pelo modelo gerencial ou novo modelo de gestão.

De acordo com Bresser Pereira (1998:25), na metade do século XX, para proteger o patrimônio público, estrutura-se um modelo de gestão do Estado denominado modelo burocrático.

Abrucio (1997) destaca que o modelo burocrático é subsidiado nos pressupostos burocráticos de Weber e foi sendo constituído, de modo geral, para substituir o patrimonialismo, a estrutura de poder constituída historicamente pelo Estado português.

Weber caracteriza o funcionalismo burocrático como fundamental para a modernização do Estado, o qual consiste em formalismo de emprego, salário, pensão, promoção, treinamento especializado e divisão funcional do trabalho, áreas bem definidas de jurisdição, processos documentários, sub e superordenação hierárquicas (Weber, 1997:39).

Exatamente a respeito das perspectivas weberianas, e de suas influências na concepção e no funcionamento do Estado, que Marcuse (1998) levantou uma série de questionamentos acerca das suas propostas e objetivos. Marcuse (1998:113) ressalta que, conforme Max We- 
ber, independentemente do que possa infligir aos homens, o capitalismo precisa, em primeiro lugar e previamente a qualquer valorização, ser apreendido como razão necessária. O autor aponta a subordinação da teoria weberiana à economia política e às exigências das forças políticas dominantes, e nada há de neutralidade em seus apontamentos, o capitalismo se converte em conceitos abstratos da racionalidade e da dominação (Marcuse, 1998:114-115).

Abrucio (1997) aponta que em torno da década de 1970 havia um esgotamento do modelo burocrático weberiano, presente até então; ele destaca que foram introduzidos, em larga escala, padrões gerenciais na administração pública, gerando um novo modo de gestão denominado modelo gerencial, ou novo modelo de gestão.

Um dos grandes propósitos do modelo gerencial foi aumentar a eficiência e a eficácia da organização pública ampliando o domínio dos processos e recursos internos. Esses modelos repercutem no funcionamento interno e em suas extensões externas. De certa forma, passa a considerar o indivíduo como cliente ou consumidor, seus métodos possibilitam maior visibilidade e controle do que os modos anteriores, quanto a resultados e serviços. A tecnologia passa a ter uma fundamental importância e o indivíduo funcionário pode ser mais controlado e cobrado, com enfoque em resultados e metas (Abrucio,1997; Bresser-Pereira e Spink, 1998).

A tendência do modo gerencial de gestão é uma forma de administrar voltada para soluções técnicas e demonstra muita proximidade com a forma de gerenciar indústrias e empresas privadas, colocando em exercício uma racionalidade semelhante que busca a eficiência.

Para a tese que respalda este artigo, os dois aspectos investigados na pesquisa para avaliar o impacto na moralidade dos indivíduos no trabalho na administração pública foram a moralidade do indivíduo e a racionalidade da administração pública. Os dois aspectos avaliados foram organizados em diversos fatores.

Os dois objetivos da pesquisa foram descritos como: identificar aspectos da racionalidade do funcionamento da administração pública que regula as relações e analisar possíveis efeitos na moralidade no contexto do trabalho do serviço público, e discutir a conduta moral no serviço público, considerando a manifestação da moralidade individual.

Observa-se, no quadro 1, que o aspecto da racionalidade e do funcionamento da administração pública está composto de dois tópicos: a sazonalidade (dos mandatos) e suas implicações, a estruturação e a manutenção da forma de trabalho.

O tópico que investiga a "sazonalidade e suas implicações" contém cinco componentes específicos: a periodicidade dos mandatos; a estabilidade (no cargo); a permissividade ou concessões; a fidelidade política; e os valores e costumes internos.

No tópico "estruturação e manutenção da forma de trabalho" estão contidos os componentes investigados: dificuldades e facilidades para o trabalho; uso do poder e prestígio; pragmatismo; avaliação pessoal de possíveis desvios na administração pública; e burocracia.

Observa-se ainda, no quadro 1, a descrição dos tópicos que fazem parte do estudo da pesquisa citada sobre a moralidade do indivíduo: relação com o outro; análise e conduta; e valores e consciência.

O tópico "relação com o outro" contém três componentes específicos: identificação ou comoção com o sofrimento alheio/comoção/compaixão; senso de justiça; e solidariedade. 
O tópico "análise e conduta" contém três componentes específicos: senso crítico e estranhamento; capacidade de julgamento; e resistência à violência/violação.

O tópico "valores e consciência" contém quatro componentes específicos: força dos interesses privados; responsabilidade e comprometimento; consciência e alienação; e valores e princípios.

\section{Quadro 1}

\section{Aspectos temáticos da pesquisa e componentes de análise}

\begin{tabular}{|c|c|c|c|}
\hline \multicolumn{4}{|c|}{ ASPECTOS TEMÁTICOS } \\
\hline \multicolumn{2}{|c|}{$\begin{array}{l}\text { Racionalidade e funcionamento da administração pública } \\
\text { Buscando verificar os componentes relacionados ao modo } \\
\text { de funcionar da administração pública, constam aspectos } \\
\text { que se referem a sua estrutura, suas regras, forma de } \\
\text { organizar o trabalho e serviços que presta e maneira de } \\
\text { gerenciar as pessoas que trabalham, conforme discutido } \\
\text { acima. }\end{array}$} & \multicolumn{2}{|c|}{$\begin{array}{l}\text { Moralidade do indivíduo no trabalho } \\
\text { Buscando verificar componentes da moral. }\end{array}$} \\
\hline TÓPICOS & COMPONENTES ESPECÍFICOS & TÓPICOS & $\begin{array}{l}\text { COMPONENTES } \\
\text { ESPECÍFICOS }\end{array}$ \\
\hline $\begin{array}{l}\text { Sazonalidade dos } \\
\text { mandatos e suas } \\
\text { implicações }\end{array}$ & $\begin{array}{l}\text { - Periodicidade dos mandatos } \\
\text { v Estabilidade } \\
\text { v Permissividade ou concessões } \\
\text { v Fidelidade política } \\
\text { v Valores e costumes internos }\end{array}$ & Relação com o outro & 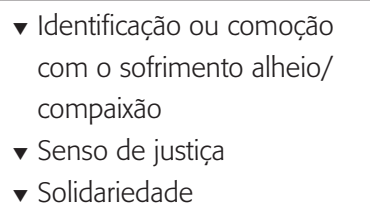 \\
\hline $\begin{array}{l}\text { Estruturação e } \\
\text { manutenção da }\end{array}$ & $\begin{array}{l}\text { - Dificuldades e facilidades para } \\
\text { o trabalho } \\
\text { v Uso do poder e prestígio } \\
\text { v Pragmatismo } \\
\text { v Avaliação pessoal de possíveis }\end{array}$ & Análise e conduta & $\begin{array}{l}\text { Venso crítico e } \\
\text { estranhamento } \\
\text { v Capacidade de julgamento } \\
\text { v Resistência à violência/ } \\
\text { violação }\end{array}$ \\
\hline forma de trabalho & $\begin{array}{l}\text { pública } \\
\text { v Burocracia }\end{array}$ & Valores e consciência & 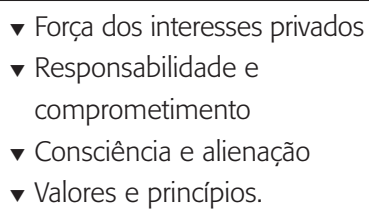 \\
\hline
\end{tabular}

Fonte: Dados da pesquisa (2010).

Os participantes da pesquisa foram ocupantes de cargos ou funções comissionados em exercício há mais de dois anos, exercendo a função de chefia, coordenação ou assessoria do Governo do Estado de São Paulo, podendo ser do quadro estável de servidores, como ocupantes de funções nomeados, sem possuir cargos de carreira. Não houve especificação de idade, sexo ou escolaridade dos sujeitos. 
A coleta de dados foi realizada utilizando como instrumento um questionário com 33 questões que visou valorizar os dados qualitativos e a análise de conteúdo, apreciando atitudes e posturas dos sujeitos participantes do estudo; portanto, questões abertas foram respondidas pessoalmente à entrevistadora. As questões foram agrupadas em cada tópico, garantindo que cada componente a ser investigado fosse abrangido por elas.

Para análise buscou-se realizar a reflexão por aspecto, identificando os objetivos relacionados aos tópicos destacados, retirando elementos das respostas dos sujeitos que contribuíam para a discussão quanto à moralidade nas condutas na administração pública.

Procurou-se agrupar as respostas por tópicos, tanto na discussão sobre a moralidade do indivíduo, quanto sobre a racionalidade da administração pública, a fim de compreender o quanto a formação do indivíduo e a forma como a instituição do serviço público são organizadas implicam moralidade presente. Consequentemente procurou-se levar, a partir da análise, indicações sobre os impactos dessa realidade na sociedade e nos cidadãos.

Foi feita uma análise das características dos sujeitos relacionando-as às suas respostas, buscando elucidar se o tempo de atuação no cargo acarreta diferente maneira de visualizar, atuar e julgar a conduta moral. Discutiu-se o tipo de vínculo estabelecido, enfim, se ocupa o cargo por ser funcionário de carreira ou exerce a função por indicação política com a administração pública, e se este interfere na postura e na moralidade do indivíduo.

Buscaram-se indicações de desafios e possibilidades de atuar na direção de fortalecer ou mudar a moralidade vigente.

\section{Análise dos dados obtidos}

\subsection{Racionalidade e funcionamento da administração pública}

Sobre a racionalidade e funcionamento da administração pública, no aspecto sazonalidade dos mandatos e suas implicações, verificou-se a relação entre a periodicidade de mandatos e a moralidade dos indivíduos agentes públicos e políticos.

De formas diferentes, todos os participantes da pesquisa apontam o fato de que ter, $a$ priori, um prazo determinado para o exercício da função de gestão concomitante com a duração do mandato do governo que o nomeou ou o designou, como também não ter garantido o cumprimento de todo o período, nem mesmo a garantia de continuidade no cargo após o fim do mandato repercutem na conduta moral. Apontam que há uma pressão sofrida por eles vinda de ocupantes de cargos superiores ou para apresentação de resultados ou pela vulnerabilidade que o cargo ocupado possui em função das instabilidades e interesses políticos, ameaçando a permanência dos mesmos no cargo.

A periodicidade dos mandatos é uma característica peculiar da administração pública e os sujeitos se adaptam a ela. A vulnerabilidade e a permanência no posto de gestão não se dão exclusivamente por capacidade profissional; os motivos que levam a exonerações são de 
baixo controle do ocupante do cargo, parecendo até mesmo que a capacidade profissional é o que é menos considerada.

Para que o desvio da conduta ocorra segundo os entrevistados, vai depender do grau de poder que o gestor possui, da permissividade encontrada, das pressões políticas e de sua formação pessoal.

A falta de participação dos funcionários nas decisões e no ambiente e a desigualdade nas relações internas foram citadas como os aspectos que incentivam tal prática. Pode-se perceber a estreita relação entre o comportamento social de buscar a satisfação de interesses pessoais e o comportamento no trabalho na administração pública. A estabilidade no emprego, por um lado, parece tranquilizar os trabalhadores públicos quanto à permanência no quadro de funcionários, não colocando em risco o emprego quando das trocas de governo e das alterações na ocupação dos cargos de confiança política. Essas características da administração pública poderiam gerar no funcionário efetivo um melhor desempenho e identificação com o trabalho que realiza. No entanto, os dados trazidos pelos entrevistados demonstram que a estabilidade não se converte, necessariamente, em comprometimento com o trabalho nem com a lisura nas condutas, mas, em parte, leva ao fortalecimento da impunidade, das concessões e, de certa forma, protege atitudes e condutas que rompem com a moralidade que considera o coletivo.

Estar na "máquina" pública como gestor possibilita perceber as dificuldades internas que impactam nos serviços prestados e na imagem pública desses serviços e que, dessa forma, diminuem a expectativa e a cobrança quanto aos resultados dos serviços para a população. Essas dificuldades estão relacionadas à burocracia e à morosidade dos procedimentos internos de trabalho, à falta de recursos financeiros, aos problemas com as exigências legais, à falta de investimento na qualificação e capacitação dos servidores, e, em alguns casos, à falta de vontade política em empreender projetos sociais.

Para parte dos entrevistados, visualizar essas falhas no funcionamento interno contribui para compreender o porquê de os resultados serem aquém do desejado pela população e minimizar a responsabilidade dos servidores públicos, e, segundo eles, não deixando de "acreditar" na administração pública.

Para outros sujeitos da amostra, estar como gestor possibilita confirmar ou piorar a imagem depreciativa que possui da administração pública. Nessa visão da administração pública estão presentes a falta de preparo dos funcionários e acordos ou interesses políticos que não consideram os interesses coletivos. Esses gestores entrevistados apontam impotência em alterar tal quadro.

Observa-se que o funcionamento e a racionalidade presentes na administração pública que sofrem implicações dos mandatos imprimem fórmulas para justificar a morosidade, o trabalho alienado e as condutas — que estão dentro do padrão esperado. Os procedimentos podem alienar, automatizar, roubar os vestígios de autonomia e tornar os indivíduos seres iguais diante da impossibilidade.

Há uma contradição presente nessa racionalidade. Por um lado, confirma que o domínio racional crescente dos processos de trabalho leva à indiferenciação. Todos podem fazer 
tudo. Por outro lado, são indivíduos que podem fazer tudo nos processos de trabalho, mas não podem mudar a realidade e, sim, conformar-se com ela.

A formação do indivíduo é a apreensão da experiência objetiva na interação social, e o trabalho é um processo social. Constata-se, até este momento, que há formas diferenciadas de avaliar e de reagir no cotidiano no trabalho, indicando que a maneira como o trabalho é estruturado e, principalmente, o significado e a relação que se estabelece com ele aparentam refletir na moralidade do indivíduo.

Tem-se até aqui indicações de que há em parte dos gestores entrevistados um movimento diverso apontado por outra parte deles. Buscam na finalidade do trabalho que realizam um objetivo que esteja além do proposto pela racionalidade da "máquina". Observa-se que esses sujeitos da amostra são tanto profissionais com cargo de carreira, quanto profissional indicado por afinidade política, como também por especificidade técnica.

Há indivíduos com mais e com menos capacidade para análises críticas da realidade que compõem. Dessa forma, os entrevistados dão indícios de que há relação entre a consciência que possuem dos fatores que compõem a realidade com a resistência oferecida aos desvios dos atributos morais. Apontam indicações de que há possibilidade de ter algum prazer no trabalho quando conseguem ter envolvimento com as necessidades coletivas presentes nas atividades que desenvolvem.

Por meio das entrevistas pôde-se verificar que a reflexão proposta por Adorno e a possibilidade de iluminar o próprio trabalho não têm sido possíveis para a maioria. Dessa forma, pode-se compreender parte da falta de entusiasmo na maior parte dos funcionários dos órgãos públicos e seus reflexos na apatia e na moralidade no trabalho. Aqueles que conseguem realizar essa reflexão apontam um facho de luz que clareia e esclarece parte da escuridão. Esses estabelecem uma luta para não se transformarem em meros recursos. Há indícios de que essa possibilidade está presente quando composta com alguns elementos, dentre eles: a coincidência entre os objetivos das tarefas profissionais e os desejos legítimos do sujeito.

Em síntese, sobre a racionalidade da administração pública em relação ao tópico sazonalidade e suas implicações, pode-se concluir que há incentivo a relações internas que buscam a satisfação de interesses privados. A moralidade está afetada e comprometida no contexto do trabalho na administração pública por meio de atos, normas, procedimentos, rotinas e ações anônimas que retiram a possibilidade de o indivíduo se reconhecer como único em um processo que precisa ser alterado, vendo-se, em sua maioria, como uma massa apática e sem autonomia. Existem sujeitos que conseguem ir em direção contrária a esse fluxo, encontrando no trabalho um sentido que vai além da autoconservação.

Sobre a estruturação e manutenção do processo de trabalho, se os recursos não são utilizados corretamente para a prestação de serviços em benefício da comunidade, se os funcionários não executam suas funções, se os cidadãos não forem bem atendidos, se os funcionários não estiverem preparados para o exercício de suas funções, não conhecerem e não estarem comprometidos com os propósitos da administração pública, tornam-se pontos que exercem influência direta e indireta na conduta moral. 
Na avaliação dos gestores ficou evidenciado que há um número maior de dificuldades do que facilidades para desenvolver as atividades profissionais esperadas para o cargo ocupado, e, dentre as dificuldades, há diversos fatores que contribuem para o rompimento com a moralidade esperada nas repartições públicas.

Ocupantes de postos estratégicos nem sempre são preparados e comprometidos com a finalidade pública de suas funções. Parte dos entrevistados aponta que os critérios para nomeação de gestores do segundo e primeiro escalões acabam por piorar a qualidade dos serviços prestados, e repercutem na conduta dos funcionários.

Apesar de a administração pública se diferenciar da iniciativa privada por não visar lucro, vê-se que os indivíduos estabelecem relações como que num mercado: há comércio de cargos, de interesses, de vantagens e, em muitos casos, a finalidade do serviço público não é considerada. Parte dos postos de comando é mantida por acordos políticos em que se pressupõem concessões e uma cultura permissiva para viabilizar projetos pessoais. Há também presente uma relação de dominação na qual aquele que detém mais poder e prestígio submete outros indivíduos a intenções imediatas distintas da prestação de serviços. Parece não haver uma rebelião contra essa dominação.

Quanto à presença de procedimentos voltados para manutenção da própria estrutura e à falta de avaliação e visualização dos resultados, do desempenho e da qualidade dos serviços prestados, aparecem nas respostas dos entrevistados, como elementos que fortalecem a ineficiência, o desinteresse na realização das tarefas e a facilitação da conduta antiética.

Grande parte do discurso dos entrevistados denota insatisfação no trabalho, e porção significativa das queixas aponta morosidade do trabalho; baixa resolução das atividades; relata ociosidade em parte significativa dos funcionários; sobrecarga em alguns; falta de cobrança e de acompanhamento do trabalho, e desempenho incipiente. Enfim, as queixas não são de trabalho extenuante ou pressão exagerada ou de uma racionalidade tecnológica com formas mecanizadas de controles, mas são de eles se verem realizando menos do que poderiam, denotam impotência diante do contexto em que se encontram.

A maior parte dos sujeitos servidores públicos entrevistados não investe energia e não tem satisfação nas atividades do trabalho; não se julga produtiva nem eficiente. A cobrança por resultados passa a ter uma fundamental importância para o indivíduo funcionário, que não se percebe controlado ao não ser cobrado.

Observaram-se nos depoimentos de grande parte dos sujeitos pesquisados o sofrimento pelo trabalho exigir menos do que poderiam oferecer e, por outro lado, uma postura de impotência e melancolia.

Os sujeitos servidores públicos que não conseguem encontrar prazer ou significado que justifique investimento libidinal, e que suas atividades caem no vazio, em parte por não serem reconhecidos e vislumbrarem pouca importância no que realizam, perdem a perspectiva, retiram a possível energia a ser investida do trabalho e lamentam-se da própria "sorte".

Há aqueles que, independentemente de qualquer fator, encontram motivação interna e conseguem investir libido em seu trabalho reconhecendo-se no que realizam - pelas entrevistas vê-se que ocorre especialmente com os funcionários que atuam diretamente com a 
população ou conseguem relacionar e visualizar efeitos e respostas do que fazem no objetivo fim da área em que atuam.

A falta total de perspectiva e de entendimento da utilidade da função exercida e sem investimento libidinal tem sido um processo tão cruel quanto a adaptação a esse sistema. É importante ser ressaltado que não há aqui a defesa de que deva ter na administração pública a ênfase no desempenho, na técnica e na eficiência, como presente no universo produtivo. Entretanto, vê-se nos depoimentos dos entrevistados que a forma como está montada a administração pública também tem anulado a consciência e praticamente anulado a possibilidade de experiência formativa nos sujeitos. A falta de sentido e de investimento libidinal é cruel. Anula a consciência e a possibilidade de experiência formativa.

\subsubsection{Desafios e possibilidades diante da racionalidade da administração pública}

Os depoimentos dos entrevistados indicam que a moralidade tem sido pouco possibilitada por determinações conscientes e internas.

A preservação das normas internas, que são elaboradas com a intenção de "moralizar", torna-se regra rígida a ser cumprida, sem análise crítica de quem a cumpre. A moral da racionalidade se sobressai à moral das relações.

Além dos processos internos e da forma de funcionar, os sujeitos confirmaram diversos atos e condutas imorais em diferentes "graus", presenciados por eles, trazendo para mais próximo de cada um a realidade discutida. Demonstram que há tentativas de investigações e de punição a atos que infrinjam o bom "uso" da "máquina" pública, alguns com processos concluídos, outros ainda a passos lentos.

Em síntese, a racionalidade da administração pública implica diretamente nas ações e condutas morais dos indivíduos. Há entre os entrevistados um misto de constatação, lamento, impotência e constrangimento.

O poder e o prestígio são utilizados por alguns para submeterem os subordinados; a moral da racionalidade sobrepõe-se à moral das relações; há falta de sentido no trabalho e nas tarefas, cujo resultado não está vinculado à necessidade da população; procedimentos burocráticos são mantidos para sustentar a própria "máquina" e desvios morais são facilitados por um contexto permissivo e de pouca cobrança ou incipiente controle.

Há presente uma ordem social ou de grupos particulares fundada na racionalidade na administração pública em que as relações são mediadas por forças dominantes que tornam uma parcela dos indivíduos pouco ou nada autônomos; as decisões e as escolhas são em grande parte controladas. Funções, desempenhos e aspirações possíveis são aqueles que o contexto da administração pública - como um ambiente administrado e com a sua própria racionalidade - pode atender. Há por parte de agentes públicos resistência e movimento no sentido contrário ao aqui colocado. 


\subsection{Moralidade do indivíduo no trabalho}

Voltando ao quadro 1, os aspectos investigados na moralidade do indivíduo estão organizados em três grupos: relação com o outro; análise e conduta, e valores e consciência.

Os sujeitos não apresentam a mesma postura e conduta, mas apontam que essas, no contexto do trabalho, necessitam de discussão e demonstram ter nelas os reflexos da formação social.

A maior parte dos entrevistados vê conformidade entre a frieza dos indivíduos no trabalho e nas outras instâncias em que estão inseridos na sociedade. No trabalho, esse "esfriamento" é justificado como necessidade profissional. O homem não está presente e sim o técnico. Os apontamentos, mesmo com opiniões diferentes sobre compaixão e solidariedade, ilustram as discussões aqui realizadas sobre a constituição do indivíduo como mediada e reflexo das exigências técnicas do processo de produção. A não solidariedade e a falta de comoção com o sofrimento do outro, enfim, a pouca capacidade de identificação com o que o outro sente demonstram a "deformação" do indivíduo produto da sociedade desumana, reforçada pela cobrança nas instituições em não expressar compaixão no trabalho.

As qualidades dos indivíduos são utilizadas para os processos de trabalho, e as características exigidas por ele são assimiladas e sedimentadas como próprias. Existem exigências ao papel profissional desempenhado pelos indivíduos que parecem ser distintas de suas próprias intenções. Essa sensação de aparente distinção entre ambas parece acentuada para quem ocupa cargos de gestão e comando de equipes, nos quais é esperada a aplicação de medidas e de procedimentos que possam ser interpretados como injustos. Há tarefas, medidas e atitudes que são exigidas do papel social e profissional e o discernimento entre essas cobranças e as intenções internas é quase indistinguível, devido à integração de ambas. E assim a consciência se mostra modelada segundo as necessidades da sociedade e da instituição. O pensamento se converteu em aplicação e disciplina.

A justiça, a solidariedade e a comoção com a dor do outro são atributos da moralidade do indivíduo difíceis de serem vividos nas relações profissionais intermediadas.

O indivíduo que reconhece em si o aumento da solidariedade e da identificação com a dor do outro, no entanto, se vê com maior capacidade de ser injusto. Deveria viver uma contradição entre as exigências externas e sua consciência, mas as defesas atuam para minimizá-la ou bloqueá-la e ele, dessa forma, não consegue escapar ao pragmatismo, exercendo de forma competente suas funções e atributos, e à obediência, seguindo ordens, cumprindo o "dever".

Diversos sujeitos apontaram que a minoria das pessoas assume o cargo com o intuito de prestar um bom serviço ao público; e para alguns essa intenção se esvazia ou perde forças com o passar do tempo no exercício do cargo.

Constata-se que, para alguns, resistir tem sido a saída possível nas circunstâncias que compõem a racionalidade do trabalho na administração pública. Os gestores pesquisados demonstram que há uma forte tendência para esvair os princípios humanos do trabalho e das relações estabelecidas. Eles apontam que é necessário ao indivíduo um esforço para garantir a manutenção desses propósitos. Aqueles indivíduos que têm consciência das forças e dos 
interesses que compõem a realidade em que estão inseridos apresentam maior facilidade de identificar-se com o trabalho que necessitam realizar, possuem atributos morais mais fortalecidos e maior clareza para considerar preceitos éticos no trabalho.

É preciso um esforço de resistência para não se sucumbir a essa frieza. Nos processos produtivos cuja racionalidade fortalece a indiferença e a perda da autonomia é necessária constante vigilância para não ocorrer a conformação e a adaptação a essa realidade, tendo-a como verdadeira e única possível.

Observa-se pelas entrevistas que a frieza do sistema afeta a solidariedade; a justiça e a identificação com a dor do outro. Nota-se que alguns entrevistados buscam iniciativas para combater a frieza no trabalho. Há indícios de que a maneira com o que o trabalho é organizado e a exigência quanto ao desempenho de um papel profissional técnico acentuem a frieza e a dificuldade em externar a compaixão, estendendo-se à sociedade. Enfim, fica inviabilizado compensar a frieza das coisas com o próprio calor, conforme orienta Benjamim (2000), se não houver mais calor no indivíduo.

Nas suposições desta pesquisa consta a intenção de identificar indivíduos comprometidos com a moralidade e com a vida, e de contribuir para a construção da ética que considere os interesses coletivos. Para isso, é fundamental que haja no indivíduo os aspectos investigados nesse momento: senso crítico e estranhamento às aberrações presentes nessa sociedade; capacidade de julgamento para fortalecer a resistência à violência e à violação.

Os entrevistados trouxeram muitos apontamentos, diversos demonstrando estranhamento a alguns fatos corriqueiros e tidos como comuns no ambiente do serviço público, outros apontando situações em que descrevem e elucidam o prejuízo moral na conduta dos indivíduos no trabalho e na sociedade. Constatou-se nesta pesquisa que, apesar das condições objetivas adversas que favorecem comportamentos ditos antiéticos, há indivíduos que mantêm a capacidade para a autorreflexão; dessa forma, têm maior facilidade em perceber os elementos que compõem a realidade social, e, especificamente aqui, capacidade de verificar fatos que ocorrem na administração pública e na sociedade e, assim, dar sentido à realidade de trabalho que vivenciam.

O prejuízo da moral demonstra a fragilidade na formação dos indivíduos com consequências avassaladoras para a consciência. A formação favorece os desvios, a violação, a transgressão do bem coletivo e a busca pelos interesses privados, revelando-se tanto no cotidiano coletivo como nos ambientes de trabalho. No serviço público, por ter uma cultura organizacional permissiva, com débeis controles, enfim, por ter como características a racionalidade apontada anteriormente, isso se agrava.

Novamente é percebido nos depoimentos dos entrevistados que a subjetividade volatizada e o "eu" capturado reduzido à inumanidade, e que abre mão dos valores que protege a convivência para viver nos valores da concorrência - descrito por Horkheimer e Adorno (1985) —, são mais intensos em alguns indivíduos e menos em outros.

É necessário tornar os servidores conscientes dos mecanismos que provocam neles a alienação, fortalecendo sua autoconsciência e seu "eu". 
Além dos comportamentos explícitos que rompem com a ética como os descritos anteriormente, a maioria dos gestores pesquisados relata a dificuldade em discernir se algumas das exigências relativas ao cargo que exerce podem comprometer a moralidade.

Para discutir os apontamentos dos entrevistados relativos à não observância de alguns procedimentos ditos criticáveis no exercício do cargo que exercem, é necessário abranger diversos pontos trazidos nas discussões anteriores. Para abordar um dos pontos, será retomada a distinção entre os conceitos de legalidade e moralidade, enfim, entre direito e justiça.

A similaridade entre ética e legalidade, direito e justiça pode fortalecer a desigualdade e a injustiça e diminuir a responsabilidade dos sujeitos por seus próprios comportamentos.

Os entrevistados demonstraram que muitos procedimentos de trabalho visam normatizar e aplicar as mesmas condições a todos, tanto aos funcionários em suas funções e tarefas, como, mais especificamente, para a população que utiliza os serviços públicos. Essas operações visam garantir um mínimo de padronização na apresentação dos serviços, nos prazos e nas garantias de alguns direitos dos usuários. Por outro lado, há procedimentos que são desvinculados da real necessidade dos cidadãos, eles são estabelecidos para controlar os controles; nas incessantes exigências formais de assinaturas; em vistos revistos, que acabam indo no sentido contrário do que o proferido. A moral perseguida é a do cumprimento dos procedimentos e normas, o sacrilégio é contrariar convenções e padrões, que muitas vezes são injustos e estão desvinculados da consciência moral. A cobrança interna não é mobilizada, a consciência se isenta devido à impotência para as decisões autônomas. "São normas, estou cumprindo os procedimentos."

Sobre a capacidade de o sujeito tomar decisões de forma autônoma, o que os pesquisados trazem é a dúvida sobre quais procedimentos na administração devem ser questionados, quais colocam em questão a moralidade. Demonstram também, entretanto, que é inviável atuar profissionalmente sem considerar tais procedimentos normatizados estipulados externamente; no entanto, muitos desses procedimentos vão no sentido contrário ao dos interesses coletivos.

Nas ponderações apresentadas pelos entrevistados há argumentos distintos. Por um lado eles contestam determinados procedimentos e normas que prevalecem em prejuízo dos indivíduos e em favor da "máquina" pública, mas ponderam que muitos deles são importantes para coibir a imoralidade; porém, diversos são apropriados com intenções escusas em favorecimento pessoal.

Todos os pesquisados apontaram que para eles a não realização dos projetos que a comunidade anseia por parte do serviço público e os possíveis desvios de conduta são de responsabilidade dos próprios indivíduos (seus interesses e valores) ou do funcionamento da administração pública (sua estrutura e dinâmica). Nenhum deles pontuou que essa responsabilidade é da sociedade. Entretanto, quando questionados em que instância deveriam ser realizadas "reformas" ou mudanças para refletir em alterações da moralidade presente nessa conjuntura, a maior parte deles aponta que seria necessária uma mudança na sociedade para repercutir no funcionamento da administração pública e nos interesses e valores dos indivíduos. 
Em síntese, nos aspectos relativos ao tópico análise e conduta do indivíduo, discutidos neste agrupamento da pesquisa, pôde-se observar que as condições objetivas no contexto do trabalho acentuam as falhas na formação da consciência, repercutem na capacidade de análise e assim nas condutas adotadas. Alguns entrevistados apresentaram críticas e demonstraram estranhamento à realidade discutida, mesmo estando como servidores públicos e compondo essa realidade há vários anos. Entretanto, uma parcela dos entrevistados pontua como comuns os fatos na administração pública que rompem com a moralidade e aparentam visualizar esses aspectos como parte de uma realidade imutável e que determina o restante, inclusive a própria postura no trabalho. Os indivíduos com menor senso crítico à violação, avaliando-a como comum e esperada, parecem ter menor capacidade de análise e julgamento da realidade bem como de estranharem os atos cotidianos. A falta de consciência inviabiliza a postura ética, tornando os indivíduos incapazes de discernir para fazerem escolhas que repercutam em si mesmos, nos outros indivíduos e no coletivo.

Os depoimentos afirmam que tanto os princípios quanto o caráter dos gestores apresentam vulnerabilidade. Percebe-se nos gestores entrevistados a fragilidade das intenções e dos "princípios" do indivíduo diante da força do funcionamento social e assim das instituições que estão estruturadas de acordo com esse funcionamento e com os valores desta sociedade.

\section{Desafios e possibilidades quanto à moralidade do indivíduo no trabalho}

Os pesquisados confirmam a frágil formação dos indivíduos e que essa favorece a perda da autonomia. Tendo o ego enfraquecido, o indivíduo toma para si os desejos externos, e convertese no recurso que a sociedade precisa para se manter soberana, injusta e desumana. Entretanto, além da constatação do comprometimento da moral, alguns entrevistados se questionaram sobre o que poderiam fazer diante dessa realidade. Alguns alegaram tristeza em perceberemse impossibilitados em alterá-la, outros se veem impotentes para isso. Outros alegam que o indivíduo também tem a capacidade de agir e que há possibilidade de influência pessoal no contexto. Na sociedade, há contradições reativas ao próprio sistema e que confirmam que o indivíduo não é algo natural e imutável, ele pode transformar-se e ir além da repetição das respostas esperadas.

Em algumas respostas dos entrevistados — sujeitos gestores públicos — há paralisia, impotência e conformação; em outras existem o questionamento e a implicação na crítica a esse funcionamento e na resistência pessoal a essa ética. Afirmando a possibilidade e necessidade de investir na crítica e na formação.

Quem preserva a capacidade de autorreflexão tem duplo sofrimento: um, por não se enquadrar na competência exigida, e outro, pela impotência em alterar a realidade que enfrenta no trabalho por meio das necessidades não satisfeitas da população que atende.

Se o indivíduo não tiver identificação com o trabalho que executa, a perda da autono-

mia e da consciência, da identificação com o outro e, consequentemente, do senso de justiça inviabiliza a capacidade de solidariedade e de prazer no trabalho. 
Aqueles sujeitos que têm maior clareza dos próprios desejos, quando esses se opõem a essas provocações, parecem conseguir se contrapor e resistir a elas. Se os desejos dos indivíduos coincidem com os valores que enaltecem os interesses particulares, esses são facilitados.

A consciência está diretamente relacionada à ética. A capacidade de autorreflexão é condição para ampliação da consciência, não conformação com a realidade e o vislumbre de alterá-la.

\section{Conclusões finais}

A análise dos dois aspectos que estruturaram a pesquisa — racionalidade da administração pública e moralidade do indivíduo - confirmou a hipótese de que ambos implicam a moralidade no trabalho dentro da administração pública.

As queixas e as situações levantadas pela pesquisa, por meio dos depoimentos dos entrevistados, são muito semelhantes, dando indícios claros de que a maneira de funcionar e a racionalidade presente nas diferentes áreas de trabalho, bem como a moralidade dos indivíduos que desempenham funções distintas nas repartições públicas, são análogas, repercutindo num padrão similar de moralidade.

A racionalidade das instituições incentiva a busca pela satisfação de interesses privados e a formação que a sociedade proporciona ao indivíduo tem contribuído para a manutenção dessa moralidade na administração pública.

Quando o trabalho resume-se em atividades rotineiras, fragmentadas, destituídas de significado, a situação se agrava, especialmente na administração pública, quando seu funcionamento é sustentado com intuito de preservar a própria racionalidade.

Apesar de no funcionamento da administração pública haver diversos fatores que não propiciam experiência formativa, há nessa realidade indivíduos que preservam a autorreflexão e mantêm o movimento contrário da primazia do econômico, na busca incessante pela ética na sociedade e, particularmente, na administração pública. Esses indivíduos são a demonstração efetiva de abertura ao movimento necessário para a vida, a justiça e a ética.

É fundamental que gestores públicos estejam comprometidos com o combate à corrupção e a fomentação da ética no trabalho. Além do controle, apuração, transparência, responsabilização e aplicação de penas severas a atos ligados à corrupção, é essencial a promoção pelo gestor de ações formativas, educacionais e reflexivas no trabalho.

O gestor público, quando no comando de equipes de trabalho, precisa implementar um modo de gestão que possibilite a ampliação da consciência dos funcionários em relação ao trabalho que estão realizando. Busque propiciar discussões sobre a finalidade das atividades que estão desempenhando e do impacto delas na sociedade e nos propósitos da instituição a que estão vinculados. Facilitar que o servidor consiga se visualizar na ação do Estado na cidade, no estado e no país, vendo-se como o propiciador do exercício da cidadania.

O modo de gerenciar assumido pelo gestor há de ser participativo e com ampliação do diálogo. Os valores presentes na maneira como são estruturadas as relações de trabalho refletem-se na ética no trabalho e na sociedade. 
Gerenciar de modo a favorecer relações saudáveis no ambiente profissional, a compreensão pelo servidor do significado e do resultado do trabalho que executa e do fim social de suas atividades, bem como a aproximação da satisfação pessoal pelas atividades profissionais que exerce é imprescindível para a ética.

Garantir o fim legítimo a que se propõe o Estado constituído para promover a cidadania, somado à efetiva prestação de serviços com qualidade, correspondentes às reais necessidades, são outros importantes aspectos a serem perseguidos.

\section{Referências}

ABRUCIO, Fernando Luiz. O impacto do modelo gerencial na administração pública: um breve estudo sobre a experiência internacional recente. Cadernos Enap, Brasília, n. 10, p. 6-25, 1997.

ADORNO, Theodor W. Crítica cultural e sociedade [1962]. In: ADORNO, Theodor W. Prismas: crítica cultural e sociedade. São Paulo: Ática, 1998. p. 76-90.

ADORNO, Theodor W. Educação após Auschwitz. In: ADORNO, Theodor W. Educação e emancipação [1970]. Rio de Janeiro: Paz e Terra, 2006. p. 119-138.

ADORNO, Theodor W. Indústria cultural [1968]. In: COHN, G. Comunicação e indústria cultural. São Paulo: Companhia Editora Nacional, 1995a. p. 287-295.

ADORNO, Theodor W. Introdução à sociologia [1968]. São Paulo: Unes, 2008.

ADORNO, Theodor W. Mínima moralia [1951]. São Paulo: Editora Ática, 1993.

ADORNO, Theodor W. Palavras e sinais: modelos críticos 2 [1969]. Petrópolis, RJ: Vozes, 1995b.

ADORNO, Theodor W. Tabus acerca do magistério [1971]. In: ADORNO, Theodor W. Educação e emancipação. Petrópolis, RJ: Vozes, 1995c. p. 87-117.

BENJAMIN, Walter. Origem do drama barroco alemão [1925]. São Paulo: Brasiliense, 1984.

BENJAMIN, Walter. Rua de mão única: obras escolhidas II [1928]. São Paulo: Brasiliense, 2000.

BRESSER-PEREIRA, Luiz C. Gestão do setor público: estratégia e estrutura para um novo estado. In: BRESSER-PEREIRA, Luiz C.; SPINK, Peter (Org.). Reforma do Estado e administração pública gerencial. Rio de Janeiro: Fundação Getulio Vargas, 1998. p. 21-38.

BRESSER-PEREIRA, Luiz C.; SPINK, Peter (Org.). Reforma do Estado e administração pública gerencial. Rio de Janeiro: Fundação Getulio Vargas, 1998.

COSTA, Jurandir F. Psiquiatria burocrática: duas ou três coisas que sei dela. In: COSTA, Jurandir F. Clínica do social: ensaios. São Paulo: Escuta, 1991. p. 65-67.

FREUD, Sigmund. O mal-estar na civilização [1930]. In: FREUD, Sigmund. Obras psicológicas completas de... Tradução de José Octávio de Aguiar Abreu. Rio de Janeiro: Imago, 1988. v. XXI. 
GOMES, Nanci F. A conduta moral na administração pública: um estudo com ocupantes de cargos comissionados. Tese (doutorado) — Instituto de Psicologia, Universidade de São Paulo, São Paulo, 2010.

HORKHEIMER, Max; ADORNO, Theodor W. Dialética do esclarecimento [1947]. Rio de Janeiro: Zahar, 1985.

HORKHEIMER, Max; ADORNO, Theodor W. Temas básicos de sociologia [1956]. São Paulo: Cultrix, 1973.

MAIA, Ari F. Apontamentos sobre ética e individualidade a partir da mínima morália. Psicologia USP, v. 9, n. 2, p. 152-166, 1998.

MARCUSE, Herbert. A ideologia da sociedade industrial: o homem unidimensional [1966]. Rio de Janeiro: Zahar, 1979.

MARCUSE, Herbert. Eros e civilização [1956]. São Paulo: Círculo do Livro, 1982.

MARCUSE, Herbert. Industrialização e capitalismo na obra de Max Weber. In: MARCUSE, Herbert. Cultura e sociedade [1964]. São Paulo: Paz e Terra, 1998.

TIBURI, Marcia. Adorno e a impossibilidade da ética. In: PUCCI, Bruno; COSTA, Belarmino; LASTÓRIA, Luiz A. C. N. (Org.). - Teoria crítica, ética e educação. Piracicaba; Campinas: Unimep; Editora Autores Associados, 2001. p. 126-145.

WEBER, Max. Burocracia e liderança política [1917]. In: WEBER, Max. Os economistas. São Paulo: Nova Abril Cultural, 1997.

Nanci Fonseca Gomes é doutora e mestre em psicologia pela Universidade de São Paulo. Dirige a empresa Emancipação Assessoria, de consultoria e treinamento em desenvolvimento humano. E-mail: nanpsi@ gmail.com. 